\title{
Chromosome Arm 3p Loss of Heterozygosity
}

National Cancer Institute

\section{Source}

National Cancer Institute. Chromosome Arm 3p Loss of Heterozygosity. NCI Thesaurus. Code C132246.

A molecular abnormality that results in monoallelic loss of function mutations located within the short arm of chromosome 3 (3p). 